\title{
Reply to Head and Keynan
}

Catia Cillóniz $\mathrm{PhD}^{1}$, José María Miro $\mathrm{MD}^{2}$, Antoni Torres $\mathrm{MD}^{1}$

${ }^{1}$ Department of Pulmonary Medicine, Hospital Clinic of Barcelona; Institut d'Investigacions Biomèdiques August Pi i Sunyer (IDIBAPS); University of Barcelona (UB); SGR 911; Ciber de Enfermedades Respiratorias (Ciberes) Barcelona, Spain.

${ }^{2}$ Infectious Diseases Service, Hospital Clinic-IDIBAPS, University of Barcelona, Barcelona, Spain.

Corresponding author: Professor Antoni Torres

Department of Pulmonary Medicine, Hospital Clinic of Barcelona

C/ Villarroel 170, 08036 Barcelona, Spain

Phone: (+34) 93-227-5779, FAX: (+ 34) 93-227-9813

Email: atorres@clinic.cat

(C) The Author(s) 2018. Published by Oxford University Press for the Infectious Diseases Society of America. All rights reserved. For permissions, e-mail: journals.permissions@oup.com. 


\section{To the Editor}

We thank Dr. Keynan et al. (1) for their interest in and comments on our work. Dr. Keynan et al., make several noteworthy points. Although community-acquired pneumonia (CAP) is frequently described as the most prevalent pulmonary infection in HIV-infected patients following pneumocystis and tuberculosis, it is well known that the prevalence of these three pulmonary infections varies with geographic region (2). In Spain, the geographical area of our study, Legionella pneumophila is the third most frequent cause of CAP in HIV-infected patients requiring hospitalization after pneumococcal and viral pneumonia (3). We understand the point of view of Keynan et al. (1) that our results in non-advanced, virologically suppressed HIV-infected patients are similar to the results reported in the South Bronx Legionella outbreak (4). In line with our study, recent data from US surveillance and reporting systems indicate that the incidence of Legionella has increased, with the cities of New York, Maryland and Connecticut having the highest incidence in the US Northeast or Mid-Atlantic regions $(5,6)$. Of course, we cannot compare the incidence of Legionella with regions such as South Africa, where despite the high prevalence of HIV-infected adults, CAP caused by Legionella is uncommon (less than $2 \%$ of all adults with CAP) and undiagnosed mainly due to the high burden of tuberculosis and HIV co-infection (7) (approximately 50\% of tuberculosis cases are HIV-infected) as concluded in the study by Wolter et al. (1).

We totally agree with the observation of Keynan et al. (1) that our results cannot be applied to advanced patients, because of more the $80 \%$ of our cases had $>200$ CD 4 cell $/ \mathrm{mm}^{3}$. In addition, more than half of our cases were virologically suppressed on antiretroviral therapy (ART), as is recognized among the limitations our study: "E 
though we included consecutive cases, $54 \%$ had virological suppression, and because of the small number of cases included, our results cannot be extrapolated to nonsuppressed HIV-infected patients"(8). We believe that these two issues as well as all our cases having received appropriate empiric antibiotic therapy provide clarification as to why our cohort of patients presented lower rates of admission to intensive care unit (ICU) and favorable outcomes.

In conclusion, as it may be difficult to identify Legionella infection in regions with higher burdens of HIV and tuberculosis, such as South Africa, clinicians must make an effort to diagnose Legionella despite the uncommon presentation, given the higher associated mortality especially due to inadequate antibiotic therapy. Finally, our results can be applied to regions such as Europe, Australia and North America were most HIV-infected patients have high CD4 cell counts and are virologically suppressed on ART. 
Financial support:

None

Acknowledgments

None

Conflicts of interest: The authors declare that they have no conflicts of interest. 


\section{References:}

1.- Head BM, Keynan Y. Similar Outcomes of Legionella pneumonia in treated HIV infection. CID

2.- Feldman C, Anderson R. HIV-associated bacterial pneumonia. Clin Chest Med. 2013 Jun;34(2):205-16.

3.- Cilloniz C, Torres A, Polverino E, et al. Community-acquired lung respiratory infections in HIV-infected patients: microbial aetiology and outcome. Eur Respir J. 2014 Jun;43(6):1698-708.

4.- Weiss D, Boyd C, Rakeman JL, et al. A Large Community Outbreak of Legionnaires Disease Associated with a Cooling Tower in New York City, 2015. Publich Health Rep $2017 ; 132: 241-250$.

5.- Dooling KL, Toews KA, Hicks LA, et al. Active bacterial core surveillance for legionellosis - United States, 2011-2013. MMWR Morb Mortal Wkly Rep 2015; 64:1190-1193.

6.- Alarcon Falconi TM, Cruz MS, Naumova EN. The shift in seasonality of legionellosis in the USA. Epidemiol Infect. 2018 Oct;146(14):1824-1833

7.- Boyles TH, Brink A, Calligaro GL, et al. : South African guideline for the management of community-acquired pneumonia in adults. J Thorac Dis. 2017;9(6):1469-502.

8.- Cillóniz C, Miguel-Escuder L, Pedro-Bonet ML, et al. Community-Acquired Legionella Pneumonia in Human Immunodeficiency Virus-Infected Adult Patients: A Matched Case-Control Study. Clin Infect Dis. 2018 Aug 31;67(6):958-961 